\title{
Prevalence and determinants of caesarean section in a rural tertiary teaching hospital: a 6-year retrospective study
}

\section{Ke Manga Reddy, Lakshmi Sailaja P.*, Shiva Charana Kodimala, Poojitha Pathakamudi, Kalpana Betha}

\begin{abstract}
Department of Obstetrics and Gynecology, Share India, Mediciti Institute of Medical Sciences, Medchal, Telangana,
\end{abstract} India

Received: 30 November 2018

Accepted: 29 December 2018

*Correspondence:

Dr. Lakshmi Sailaja P.,

E-mail: sailaja.kandala@gmail.com

Copyright: (c) the author(s), publisher and licensee Medip Academy. This is an open-access article distributed under the terms of the Creative Commons Attribution Non-Commercial License, which permits unrestricted non-commercial use, distribution, and reproduction in any medium, provided the original work is properly cited.

\begin{abstract}
Background: Caesarean section is the most commonly performed surgery in obstetrics and there is a rise in caesarean section rates in recent times. This study was undertaken to know the changing trends in caesarean section rate in a rural hospital and to examine the indications contributing to it. The objective of the present study was to know the prevalence and changing trends in caesarean section over the last 6 years (April 2012-March 2018).

Methods: Demographic data for all the deliveries, mode of delivery and indications of caesarean sections performed from April 2012 to March 2018 that occurred at MIMS were collected in a retrospective manner.

Results: Among a total of 12,522 women delivered during the study period of 6 years, 44.93\%, 48.49\%, 48.41\%, $50.9 \%, 45.48 \%$ and $49.62 \%$ were delivered by caesarean section during 2012-2013, 2013-2014, 2014-2015, 20152016, 2016-2017 and 2017-2018 respectively. Increase in repeat caesarean section is the primary reason for these increased rates followed by fetal distress. There is a rise in the repeat caesarean section from $44.36 \%$ in $2012-2013$ to $55.67 \%$ in $2016-2017$ and $47 \%$ in $2017-2018$. Whereas primary caesarean section rate reduced from $55.63 \%$ in $2012-$ 2013 to $44.32 \%$ in $2016-2017$ and $53 \%$ in $2017-2018$.

Conclusions: As repeat caesarean section and fetal distress are the most common causes of caesarean section we need to address these to bring down the caesarean section rate.
\end{abstract}

Keywords: Caesarean section rate, Indications, Primary caesarean section, Repeat caesarean section

\section{INTRODUCTION}

Caesarean section is one of the commonly performed surgical procedures in obstetrics. ${ }^{1}$ It was introduced in clinical practice as a lifesaving procedure for the mother and/or the baby.One of the most dramatic features of modern obstetrics is the increase in caesarean section rates. ${ }^{2,3}$ Caesarean section rate has increased in different parts of the world, both in developed and developing countries over the last three decades..$^{4,5} 6$ There is increase in trend in both primary and repeat caesarean rate. $^{7}$ Although WHO has recommended that CS rates should not be more than $15 \%$, as rates above these are not beneficial, the incidence of CS rates is increasing. ${ }^{8}$ In
India, the CS rate has increased to $18 \%$ in 2016 as compared to $3 \%$ in $1992 .^{9,10}$ In some states like Telangana, Tripura, West Bengal, Kerala, Andhra Pradesh and Tamil Nadu, the rate is alarmingly high, with Telangana $(74.9 \%)$ having the highest number of $\mathrm{C}$ section deliveries in private hospitals. ${ }^{10}$

The reasons for the increase are multifaceted. Previous caesarean section, fetal distress, especially its detection by continuous electronic fetal monitoring, more liberal use of caesarean section for breech presentation, abdominal delivery of growth retarded fetus, delayed child bearing, increasing body mass, multiple gestation, prematurity, maternal request and fear of litigation are 
commonly cited causes. ${ }^{11}$ As with any surgery, caesarean sections are associated with short- and long-term risks which can extend many years beyond the delivery and affect the health of the woman, her child and future pregnancies. Caesarean section is associated with increased risk of blood transfusion, hysterectomy and death as compared to vaginal delivery. ${ }^{12}$

A uterine scar can increase risk of uterine rupture, placenta accreta and placenta previa in subsequent pregnancies. ${ }^{13}$ Babies are also at increased risk of respiratory distress syndrome, accidental injuries due to surgical knife and iatrogenic prematurity. This increasing trend must be stopped and even reversed without detriment to a continuing improvement in maternal and fetal health. ${ }^{14}$ Identifying the trends in rates and indications contributing to caesarean section would help in formulating guidelines to reduce the caesarean section rate. $^{15}$

As caesarean section rates tend to vary widely with clinical and socio-demographic factors of patients and attitudes of health providers, it has been suggested that national caesarean delivery rates do not reflect what is happening locally. ${ }^{16}$ It supports the need for monitoring rates at the level of individual hospital or physician. ${ }^{17}$

India has substantial variations in the availability, quality and acceptability of health care facilities including maternal health.

Tertiary care centers have high caesarean section rates but areas where health care facilities are not available may have maternal deaths due to lack of C-section facilities. ${ }^{18}$ It would therefore helpful to assess caesarean section rates in tertiary health care facilities which could be in some way be representative of $\mathrm{C}$-section rates of the population catered by that centre.

The purpose of this study was to find out the caesarean section rate in our hospital, to identify the reason for the rise in caesarean section rate and to identify areas where caesarean section rates can be reduced.

The aim of the present study is to assess the prevalence and determinants of caesarean section among all the births occurring at Mediciti Institute of Medical Sciences (MIMS), a rural tertiary teaching hospital in Telangana for a period of 6 years from April 2012 to March 2018.

The objective of the present study to estimate the prevalence of caesarean section at MIMS. To study the determinants associated with caesarean section. To study the change in trends in prevalence and determinants of $\mathrm{CS}$ in the last 6 years.

\section{METHODS}

This retrospective study was conducted at Mediciti Institute of Medical Sciences, a rural tertiary teaching hospital located $35 \mathrm{~km}$ from the city of Hyderabad in Telangana state, India.

\section{Inclusion criteria}

- All caesarean sections conducted at MIMS in a time period of 6 years from April 2012 to March 2018.

All deliveries in the hospital and pregnancy outcomes are recorded in the birth register. To compare the caesarean delivery rates over the last 6 years from April 2012 to March 2018, all the details of women and their pregnancy outcomes were collected from the hospital records. Indications for caesarean sections were studied and analyzed.

The categories of indications for caesarean section like fetal distress, multiple gestation, mal-presentation, nonprogression of labour, cephalo-pelvic disproportion, maternal indications, fetal indications, obstetric indications and repeat caesarean sections etc were studied.

In the current study, the category of fetal distress includes fetal distress during labour, non-reassuring and abnormal NST when not in labour and abnormal umbilical artery doppler study.

Maternal indications are the maternal conditions anteceding the pregnancy that could complicate delivery like post-myomectomy, vesico-vaginal fistula and medical diseases. Obstetric indications are the conditions brought about by present pregnancy like placenta previa, abruptio placentae, placenta accreta and cord prolapse. Fetal indications include fetal growth restriction, prematurity and congenital malformations in which vaginal delivery is not possible.

For repeat caesarean sections, LSCS was performed either electively or in emergency when the patient presented in labour or with scar tenderness. Trial of labour was not given even after one previous caesarean section until and unless women come in active stage of labour.

\section{Statistical analysis}

All the data was then entered in Microsoft Excel spreadsheet and analyzed.

Total, primary and repeat caesarean section rates were calculated for each year. Relative contribution of each indication to the total caesarean section rate in that particular year was calculated as percentage and changing trends in caesarean section were analyzed.

\section{RESULTS}

A total of 2119, 2229, 2520, 1869, 2036 and 1749 live births occurred in hospital in 2012-2013, 2013-2014, 
2014-2015, 2015-2016, 2016-2017 and 2017-2018 respectively.

Table 1: Rate of caesarean sections in 6 years.

\begin{tabular}{|l|l|l|l|l|}
\hline $\begin{array}{l}\text { Time } \\
\text { period } \\
\text { (April- } \\
\text { March) }\end{array}$ & $\begin{array}{l}\text { Total no. } \\
\text { of } \\
\text { deliveries }\end{array}$ & $\begin{array}{l}\text { No. of } \\
\text { caesarean } \\
\text { sections }\end{array}$ & $\begin{array}{l}\text { Rate of } \\
\text { CS per } \\
\text { 1000 live } \\
\text { births }\end{array}$ & $\%$ \\
\hline $2012-2013$ & 2119 & 949 & 449.33 & 44.93 \\
\hline $2013-2014$ & 2229 & 1081 & 484.97 & 48.49 \\
\hline $2014-2015$ & 2520 & 1220 & 481.4 & 48.41 \\
\hline $2015-2016$ & 1869 & 953 & 509.8 & 50.98 \\
\hline $2016-2017$ & 2036 & 916 & 454.8 & 45.48 \\
\hline $2017-2018$ & 1749 & 868 & 496.3 & 49.63 \\
\hline
\end{tabular}

Table 1 illustrates the rate of LSCS over the 6 years, which increased from 2012 -2013 to 2017 -2018 however decreased in 2016-2017 in comparison to 2015-2016. The average annual rate increased from 449.33 per 1000 live births $(44.93 \%)$ in $2012-2013$ to 509.8 per 1000 live births $(50.98 \%)$ in $2015-2016$ and then decreased to
454.8 per 1000 live births (45.48\%) in 2016-2017 and 496.3 per 1000 live births $(49.63 \%)$ in 2017-2018.

Table 2 shows the rate of LSCS according to gravidity. The majority of caesarean sections were in multigravidae which has increased from $58.90 \%$ to $71.09 \%$. Caesarean section rates in primis have decreased from $41.09 \%$ to $28.91 \%$.

\section{Table 2: Caesarean section rate depending on status} of gravida.

\begin{tabular}{|l|l|l|}
\hline $\begin{array}{l}\text { Time period } \\
\text { (Apri- } \\
\text { March) }\end{array}$ & $\begin{array}{l}\text { No. of CS in } \\
\text { primigravidae } \\
(\%)\end{array}$ & $\begin{array}{l}\text { No. of CS in } \\
\text { multigravidae } \\
(\%)\end{array}$ \\
\hline $2012-2013$ & $390(41.09)$ & $559(58.90)$ \\
\hline $2013-2014$ & $423(39.13)$ & $655(60.59)$ \\
\hline $2014-2015$ & $496(40.65)$ & $724(59.34)$ \\
\hline $2015-2016$ & $351(36.83)$ & $602(63.17)$ \\
\hline $2016-2017$ & $309(33.73)$ & $607(66.27)$ \\
\hline $2017-2018$ & $251(28.91)$ & $617(71.09)$ \\
\hline
\end{tabular}

Table 3: Pattern of age distribution among the caesarean section cases.

\begin{tabular}{|l|l|l|l|l|l|l|}
\hline \multicolumn{7}{|c|}{ A bsolute no. of CS cases in different age groups (\%) } \\
\hline Age group (years) & $2012-2013$ & $2013-2014$ & $2014-2015$ & $2015-2016$ & $2016-2017$ & $2017-2018$ \\
\hline Below 20 & $52(5.47)$ & $60(5.55)$ & $76(6.22)$ & $55(5.77)$ & $50(5.45)$ & $31(3.57)$ \\
\hline $20-25$ & $722(76.08)$ & $786(72.71)$ & $883(72.38)$ & $662(69.46)$ & $628(68.56)$ & $588(67.74)$ \\
\hline $26-30$ & $148(15.59)$ & $186(17.20)$ & $226(18.52)$ & $211(22.14)$ & $209(22.81)$ & $206(23.74)$ \\
\hline $31-35$ & $22(2.31)$ & $46(4.25)$ & $33(2.70)$ & $25(2.62)$ & $24(2.62)$ & $38(4.37)$ \\
\hline Above 35 & $5(0.52)$ & $3(0.27)$ & $2(0.16)$ & $0(0)$ & $5(0.54)$ & $5(0.57)$ \\
\hline
\end{tabular}

Table 3 shows age distribution of the women which ranged from 18 to 40 years. In the year 2012-2013, majority of caesarean sections were done among women aged 20-25 years $(76.08 \%)$.

But over the years, the rates of CS in these women decreased to $67.74 \%$ while the rates of CS rose in women aged 26-30 years (from $15.59 \%$ to $23.74 \%$ ).

Table 4: Incidence of term and preterm caesarean section.

\begin{tabular}{|l|l|l|}
\hline $\begin{array}{l}\text { Time period } \\
\text { (April-March) }\end{array}$ & $\begin{array}{l}\text { No. of term CS } \\
(\%)\end{array}$ & $\begin{array}{l}\text { No. of preterm } \\
\text { CS }(\%)\end{array}$ \\
\hline $2012-2013$ & $844(88.93)$ & $105(11.06)$ \\
\hline $2013-2014$ & $1005(92.96)$ & $76(7.03)$ \\
\hline $2014-2015$ & $1132(92.78)$ & $88(7.21)$ \\
\hline $2015-2016$ & $911(95.59)$ & $42(4.40)$ \\
\hline $2016-2017$ & $874(95.41)$ & $41(4.47)$ \\
\hline $2017-2018$ & $733(84.44)$ & $135(15.56)$ \\
\hline
\end{tabular}

Table 4 shows the rates of term and preterm LSCS. Preterm LSCS decreased from $11.06 \%$ in 2012 - 2013 to
$4.47 \%$ in $2016-2017$ but increased to $15.56 \%$ in $2017-$ 2018. Term LSCS has increased from $88.93 \%$ to $95.41 \%$ from 2012 to 2017 but decreased to $84.44 \%$ in 2108 .

Table 5 illustrates the rate of primary LSCS which ranged between $44 \%-61 \%$ and repeat LSCS ranged between $38 \%-55 \%$.

Table 6 shows the changing trend in elective and emergency CS.

Table 5: Incidence of primary and repeat caesarean section.

\begin{tabular}{|l|l|l|}
\hline $\begin{array}{l}\text { Time period } \\
\text { (A pri-March) }\end{array}$ & $\begin{array}{l}\text { No of primary } \\
\text { CS (\%) }\end{array}$ & $\begin{array}{l}\text { No. of repeat } \\
\text { CS }(\%)\end{array}$ \\
\hline $2012-2013$ & $528(55.63)$ & $421(44.36)$ \\
\hline $2013-2014$ & $609(56.33)$ & $472(43.66)$ \\
\hline $2014-2015$ & $748(61.31)$ & $472(38.68)$ \\
\hline $2015-2016$ & $487(51.10)$ & $466(48.89)$ \\
\hline $2016-2017$ & $406(44.32)$ & $510(55.67)$ \\
\hline $2017-2018$ & $460(53)$ & $408(47)$ \\
\hline
\end{tabular}


Percentage of emergency CS has decreased from $78.71 \%$ in 2012-2013 to $59.68 \%$ in 2017-2018. Elective CS rates have increased from $21 \%$ to $40 \%$ over these 6 years.

Table 7 shows the contribution of various indications to the total caesarean section rates.

The majority of increase is attributable to repeat caesarean section (44\%-55\%) followed by fetal distress (14-28\%) across the years. Other indications show no discernable trends.
Table 6: Incidence of emergency and elective caesarean section.

\begin{tabular}{|l|l|l|}
\hline $\begin{array}{l}\text { Time period } \\
\text { (A pril-March) }\end{array}$ & $\begin{array}{l}\text { No. of emergency } \\
\text { CS (\%) }\end{array}$ & $\begin{array}{l}\text { No. of elective } \\
\text { CS (\%) }\end{array}$ \\
\hline $2012-2013$ & $747(78.71)$ & $202(21.28)$ \\
\hline $2013-2014$ & $849(78.53)$ & $232(21.46)$ \\
\hline $2014-2015$ & $920(75.40)$ & $300(24.59)$ \\
\hline $2015-2016$ & $665(69.77)$ & $288(30.22)$ \\
\hline $2016-2017$ & $586(63.97)$ & $330(36.02)$ \\
\hline $2017-2018$ & $518(59.68)$ & $350(40.32)$ \\
\hline
\end{tabular}

Table 7: Contribution of each indication to total caesarean sections in percentage

\begin{tabular}{|l|l|l|l|l|l|l|}
\hline \multicolumn{7}{|c|}{ Absolute no. of cases of each indication contributing to caesarean sections (\%) } \\
\hline Time period & $2012-2013$ & $2013-2014$ & $2014-2015$ & $2015-2016$ & $2016-2017$ & $2017-2018$ \\
\hline Previous LSCS & $421(44.36)$ & $472(43.66)$ & $512(41.97)$ & $436(45.75)$ & $514(56.11)$ & $452(52.07)$ \\
\hline Fetal distress & $270(28.45)$ & $270(24.98)$ & $335(27.46)$ & $158(16.58)$ & $137(14.96)$ & $203(23.39)$ \\
\hline Cephalo-pelvic disproportion & $93(9.80)$ & $113(10.45)$ & $107(8.77)$ & $96(10.07)$ & $85(9.28)$ & $53(6.11)$ \\
\hline Non-progression of labour & $43(4.53)$ & $47(4.35)$ & $53(4.34)$ & $84(8.81)$ & $46(5.02)$ & $52(5.99)$ \\
\hline Fetal indication & $44(4.63)$ & $50(4.62)$ & $53(4.34)$ & $65(6.82)$ & $48(5.24)$ & $14(1.61)$ \\
\hline Maternal indication & $18(1.90)$ & $47(4.35)$ & $70(5.74)$ & $70(7.34)$ & $42(4.58)$ & $26(2.99)$ \\
\hline Obstetric indication & $22(2.32)$ & $28(2.59)$ & $67(5.49)$ & $35(3.67)$ & $29(3.17)$ & $14(1.61)$ \\
\hline Malpresentation & $38(4.50)$ & $54(4.99)$ & $23(1.88)$ & $9(0.94)$ & $15(1.64)$ & $54(6.23)$ \\
\hline
\end{tabular}

\section{DISCUSSION}

Today there is concern over the rising caesarean section rates in both developed and developing countries across the world. ${ }^{2,3}$ The rates of both primary and repeat caesarean section have been on the rise. ${ }^{19}$ In present study, the increase in average annual caesarean delivery rate, from $44.93 \%$ in $2012-2013$ to $49.63 \%$ in $2017-2018$, is consistent with the findings of other investigators. Barber et al showed an increase from $26 \%$ to $36.5 \%$ between 2003 and 2009 and it changed from 10.6\% in 1997 to $19.1 \%$ in 2006 in case of Ba'aqeel. ${ }^{19,20}$ The reported increase in caesarean rate in Tanzania by Litorp et al has been higher, rising from $19 \%$ in 2000 to $49 \%$ in $2011 .^{5}$ Saha et al reported a rate of $29 \%$ in 2007 in Kolkata. The trend over time in caesarean section has shown considerable variations from across different countries. $^{21}$

Over the years, there is an increase in LSCS in older women compared to younger women in the present study. There has been a demographic transition of our area from rural to semi-urban in these six years which has improved the socio-economic status of women and that has translated into higher education and delayed childbearing. Risk factors like diabetes, hypertension increase with age which increases complications in the antenatal period which may require termination by caesarean section. The reason for high caesarean section rate in our hospital is because of referral of complicated pregnancies from the periphery which has led to increase in LSCS at pre-term gestations. The largest contributor to the rise in caesarean section rate is repeat caesarean section in the present study which is consistent with the findings of a study in the Welsh population conducted by Choudhary et al, and studies by Stavrou et al and Helen Litorp et al. ${ }^{22,23,24}$ In present study, contribution by repeat caesarean section has increased from $44.36 \%$ (198.68 per 1000 live births) in $2012-2013$ to $56.11 \%$ (252.46 per 1000 live births) in 2016-2017. There has been a rise in elective LSCS as most of repeat LSCS were done as planned procedures. Emergency LSCS rates declined which indicates better intrapartum care.

Our analysis clearly captures the so-called domino effect of caesarean section use: as the rates of caesarean section increases, more women will be in need of repeat caesarean section. This is because of the increase in repeat caesarean section after previous section in multigravidae. A number of factors will determine the success of VBAC (Vaginal Birth After Caesarean Section) with lower segment transverse uterine scar which can be assessed on taking a thorough clinical history and performing relevant examination for the woman. Inter-delivery interval less than 24 months is one of the factors associated with decreased probability of success. Women in our area mostly rely on lactational amenorrhea as contraceptive method of choice and most conceive within a year after caesarean section. Though sonography permits accurate assessment of the lower uterine segment thickness in women with previous 
caesarean section and can be used to predict the risk of uterine rupture during TOLAC (Trial of Labour After Caesarean Section), the clinical applicability of this approach is being questioned. There is a need for more standardized measurement techniques so as to recommend cut-off values.

VBAC should not be undertaken in units where facilities such as emergency transfer to theatre, blood transfusion are not available. In view of short inter-pregnancy interval, less than adequate blood bank facilities and couples not willing for TOLAC when explained the risks of VBAC have led to these decreased rates in our setting. The subject of delivery of a woman with one prior scar is controversial. ${ }^{25}$ Many studies have recommended that the option of VBAC should be given to women with one prior scar. ${ }^{26}$ Whereas study done by McMahon et al, have reported higher rates of maternal and fetal morbidity exist after VBAC as compared to repeat caesarean section. ${ }^{27}$

The second leading cause of caesarean section in present study was fetal distress. However, the caesarean section for fetal distress has decreased from $28.45 \%$ (127.42 per 1000 live births) in 2012-2013 to $14.96 \%$ (67.29 per 1000 live births) in 2016-2017 which is a good indicator of better intra-partum surveillance. Fetal monitoring was done with help of stethoscope, fetal doppler, noting presence of meconium stained liquor and continuous fetal monitoring during labour. In a study done by Anderson et al, previous one caesarean, fetal distress and dystocia accounted for most of the cases of caesarean section. ${ }^{28}$ In the present study relative contribution of non-progression of labour and cephalo-pelvic disproportion together to total caesarean section reduced from $14.33 \%$ in 2012 2013 to $12.10 \%$ in 2017-2018. In a population-based study done in Bangladesh, these accounted for $16 \%$ of total caesarean sections. ${ }^{29}$

The present study also showed an increase in caesarean section for maternal indications like uncontrolled hypertension, pre-eclampsia, eclampsia and gestational diabetes mellitus from $1.9 \%$ ( 8.49 per 1000 live births) in $2012-2013$ to $2.99 \%$ ( 14.86 per 1000 live births) in 2017-2018 which reflects the rise in maternal medical complications. Caesarean section for obstetric indications like placenta previa, placenta accreta and abruptio placenta has increased from $2.32 \%$ ( 10.38 per 1000 live births) in $2012-2013$ to $3.17 \%$ ( 14.24 per 1000 live births) in 2016-2017 which is because of increase in pregnancies in scarred uterus and increase in medical complications. There is no discernible trend in the other indications to possibly account for the increasing caesarean section rates.

Japan is the only country in the world to report a reduction in the CS rate. Decrease occurred in LSCS for women with spontaneous or induced nulliparous women and women with previous caesarean sections. So, evidence-based interventions and programmes to reduce primary and repeat CS are needed. According to the recently released guidelines by the World Health Organisation, a structured, mandatory second opinion for caesarean section indication in clinical settings is recommended to reduce caesarean births. ${ }^{30}$

Goals for achieving an optimal caesarean delivery rate should be based on maximizing the best possible maternal and neonatal outcomes, taking into account available medical and health resources and maternal preferences. The decision for primary caesarean section is very important and every effort should be made in primigravida for vaginal delivery by a carefully supervised monitoring of labour.

\section{CONCLUSION}

The overall CS rate in this study has increased from 2012-2013 to 2017-2018. Significant increase is seen in repeat caesarean section rate in the present study. Increasing trial of scar in women with previous caesarean section is an important intervention in reducing caesarean section. Though the primary caesarean section rate has decreased from 2012-2013 to 2017-2018, further efforts should be put on reducing primary caesarean section rate as it will also reflect in a decreased secondary LSCS rate. Measures such as establishing a definite indication for caesarean section, precise interpretation of fetal heart rate tracings, judicious use of oxytocin, monitoring with partogram, instrumental vaginal delivery, use of external cephalic version in breech, audit of the indications of caesarean section will help in reducing the rates of LSCS.

\section{Funding: No funding sources}

Conflict of interest: None declared

Ethical approval: The study was approved by the Institutional Ethics Committee

\section{REFERENCES}

1. Mittal S, Pardeshi S, Mayadeo N, Mane J. Trends in Caesarean Delivery : rate and indications. J Obstet Gynecol India. 2014;64(4):251-4.

2. Turner MJ. Delivery after one previous caesaren section. Am J Obstet gynaecol.1997;176(4):741-4.

3. Oladapo OT, Sotunsu JO, Sule-Odu AO. The rise in caesarean birth rate in Sagamu, Nigeria: reflection of changes in obstetrics practice. J Obstet Gynaecol. 2004;24(4):377-81.

4. Zizza A, Tinelli A, Malvasi A, Barbone F, Stark M, De Donno MA, et al. Caesarean section in the world :a new ecological Approach. J Prev Med Hyg. 2011;52(4):161-73.

5. Litorp H, Kidanto H, Nystrom L, et al. Increasing caesarean section rates among low risk groups: a panel study classifying deliveries according to Robson at a university hospital in Tanzania. BMC Pregnancy Childbirth. 2013;13(1):107.

6. Ray A, Jose S. Analysis of caesarean section rates according to Robson's ten group classification system and evaluating the indications within the 
groups. Int J Reprod Contracept Obstet Gynecol 2017;6(2):447-51.

7. Agarwal M, Verma M, Garg A. Changing trends in caesarean delivery: rate and indications. Int $\mathrm{J}$ reprod Contracept Obstet Gynecol 2016;5(10):3522-4.

8. World Health Organization. Monitoring emergency obstetric care: a handbook. Geneva, Switzerland; 2009

9. International Institute for Population Sciences (IIPS) and Macro International. National Family Health Survey (NFHS 1), 1992-1993. Mumbai, India:IIPS, 1995

10. International Institute for Population Sciences (IIPS) and Macro International. National Family Health Survey (NFHS 4), 2016-2017. Mumbai, India:IIPS, 2017

11. Tollanes MC. Increased rate of Caesarean sections causes and consequences. Tidsskr Nor Laegeforen. 2009;129(13):1329-31.

12. Villar J, Carroli G, Zavaleta N, et al: Maternal and neonatal individual risks and benefits associated with caesarean delivery: multicentre prospective study. BMJ 2007, 335(7628):1025-9.

13. Daltveit AK, Tollanes MC, Pihlstrom H, Irgens LM: Caesarean delivery and subsequent pregnancies. Obstet Gynaecol. 2008;111(6):1327-34.

14. Beazley JM. Caesarean section. In: Chamberlain G, Turnbull SA, editors. Obstetrics. 1st ed. Churchill Livingstone Publications; 1993. P.857-65

15. NotzonFC, Cnattingius S, Bergijo P, Cole S, Taffel $\mathrm{S}$, Irgens L, et al. Caesarean Section delivery in the 1980s; International comparison by indication. AmJ Obstet Gynaecol. 1994;170(2):495-504.

16. Richman VV. Lack of local reflection of national changes in cesarean delivery rates: The Canadian experience. Am J Obstet Gynecol. 1999;180(2):3935.

17. Gregory KD. Monitoring, risk adjustment and strategies to decrease caesarean rates. Curr Opin Obstet Gynecol. 2000;12(6):481- 6.

18. Halpern SH, Leighton BL. The risks of lowering the caesarean delivery rate. $\mathrm{N}$ Engl $\mathrm{J}$ Med 1999:341(1):54-7.

19. Barber EL, Lundsberg L, Belanger K, Pettker CM, Funai EF, Illuzzi JL. Indications contributing to the increasing delivery rate. Obstet Gynecol.2011;118(1):29-38.

20. Ba'aqeel. Caesarean delivery rates in Saudi Arabia: a ten-year review. Ann Saudi Med.2009;29(3):179-83.
21. Saha S, Saha S, Das R, Chakraborty M, Bala HS, Naskar P. A paradigm shift to check the increasing trend of caesarean Delivery is the need of hour: but how ? J Obstet Gynaecol India. 2012;62(4):391-7.

22. Choudhary AP, Dawson AJ. Trends in indications for caesarean sections over \& years in a Welsh district general hospital. J Obstet Gynaecol.2009;29(8):714-7.

23. Stavrou EP, Ford JB, Shand AW, Morris JM, Roberts CL. Epidemiology and trends for caesarean section births in SouthWales, Australia: a population based study .BMC Preg ChildBirth 2011;11(1):8.

24. Litorp H, Kidanto HL, Nystrom L, Darj E, Essén B. Increasing caesarean section rates among low risk groups : a panel study classifying deliveries according to Robson at a university hospital in Tanzania. BMC Pregnancy and Childbirth 2013,13(1):107.

25. Guise JM, Berlin M, McDonagh M, Osterweil P, Chan B, Helfand M. Safety of vaginal birth after caesarean: A systematic review. Obstet Gynaecol. 2004;103(3):420-9.

26. National Institutes of Health Consensus Development Conference Statement. Vaginal birth Caesarean: new insights March 8-10;115(6):1279-95

27. McMahon MJ, Luther ER, Bowles WA Jr, Olshan AF. Comparison of trial of labour with an Elective caesarean section. N Engl J Med. 1996; 335(10);68990.

28. Anderson GM, Lomas J. Determinants of increased caesarean birth rate. Ontario data 1979-82. N Engl J Med. 1984:311(14):887-92.

29. Begum T, Rahman A, Nababan H, Hoque DM, Khan $\mathrm{AF}$, Ali $\mathrm{T}$, et al. Indications and determinants of caesarean section delivery: Evidence from a population-based study in Matlab, Bangladesh. PloS one. 2017;12(11):e0188074.

30. Mandatory Second Opinion to reduce Unnecessary C- Sections: WHO 2018 Guidelines. Available at https://speciality.medicaldialogues.in/havemandatory-second-opinion-to-reduce-unnecessary-csections-who-2018-guidelines/.

Cite this article as: Reddy KM, Sailaja LP, Kodimala SC, Pathakamudi P, Betha K. Prevalence and determinants of caesarean section in a rural tertiary teaching hospital: a 6-year retrospective study. Int J Reprod Contracept Obstet Gynecol 2019;8:560-5. 